\title{
Effects of different weights and lifting postures on balance control following repetitive lifting tasks in construction workers
}

\begin{abstract}
Repetitive lifting tasks have detrimental effects upon balance control and may contribute towards fall injuries, yet despite this causal linkage, risk factors involved remain elusive. This study evaluates the effects of different weights and lifting postures on balance control using simulated repetitive lifting tasks. Twenty healthy male participants underwent balance control assessments before and immediately after a fatiguing repetitive lifting tasks using three different weights in a stoop ( 10 participants) or a squat ( 10 participants) lifting posture. Balance control assessments required participants to stand still on a force plate with or without a foam (which simulated an unstable surface) while center of pressure ( $\mathrm{CoP})$ displacement parameters on the force plate was measured. Results reveal that: i) increased weight (but not lifting posture) significantly increases CoP parameters; ii) stoop and squat lifting postures performed until subjective fatigue induce a similar increase in CoP parameters; and iii) fatigue adversely effected the participant's balance control on an unstable surface vis-a-vis a stable surface. Findings suggest that repetitive lifting of heavier weights would significantly jeopardize individuals' balance control on unstable supporting surfaces, which may heighten the risk of falls. This research offers an entirely new and novel approach to measuring the impact that different lifting weights and postures may have upon worker stability and consequential fall incidents that may arise.
\end{abstract}

\section{KEYWORDS}

Balance control, falls, fatigue, lifting posture, weight.

\section{INTRODUCTION}

Fall injuries are a leading cause of fatal injuries and the second most common cause of non-fatal injuries in the construction industry (Center to Protect Workers' Right, 2007). According to the United States Bureau of Labor Statistics (BLS), fall injuries in the construction industry accounted for $32 \%$ of all work-related deaths (BLS, 2006a) and 34\% of non-fatal injuries (BLS, 2006b). Fallrelated injuries are also prevalent amongst the general public, especially among the elderly (Zigel et al., 2009; Jiang et al., 2011). Slips, trips and loss of balance are common contributing factors to 
fall injuries on a level surface (Hsiao and Simeonov, 2001; Lipscomb et al., 2006). While slips and trips can be mitigated by ergonomic design of the working environment, balance control is inherently far more complex and relies upon the coordination of multiple sensory systems (visual, vestibular, and proprioception/somatosensory), the motor system and central nervous system (Punakallio, 2005; Horak, 2006). Impaired balance control (i.e., increased postural sway) has been linked to an increased risk of falls (Prieto et al., 1996; Corbeil et al., 2003; Paillard, 2012). Therefore, any potential interventions to minimize workplace falls and concomitant injuries sustained, must ensure that balance control is not impaired by personal, environmental and taskrelated risk factors (Hsiao and Simeonov, 2001).

Amongst the many task related hazards confronting construction workers, repetitive lifting tasks presents a prominent and significant risk (Marras et al., 1995; Sparto et al., 1997a; Latza et al., 2002). Repetitive lifting tasks involving different weights and/or awkward lifting postures (e.g., stoop or squat) are common for tradesmen handling masonry, concrete reinforcement, scaffolding and paving (Goldsheyder et al., 2002; Hess et al., 2003; Albers and Estill, 2007). For example, rebar workers repetitively lift different weights of rebars (ranging from 7 to $17 \mathrm{~kg}$ ) during their typical working day. In turn, different weights have differential effects upon spinal biomechanics (e.g., causing muscle fatigue) and heavyweights can affect workers' balance control (Hagen and Harms-Ringdahl, 1994; Straker and Duncan, 2000). The stoop lifting posture induces greater back extensor muscle activity and stronger perceived back muscle fatigue than squat lifting (Hagen and Harms-Ringdahl, 1994). However, postural perturbations during repetitive lifting (using either posture) overloads the musculoskeletal tissue and impairs balance control thus elevating the risk of loss of balance, fall incidents and consequential injuries (Chow et al., 2005). This is because postural perturbations during repetitive lifting tasks shift the body's center of mass to move beyond the base of support to create excessive center of pressure (CoP) displacement (Kincl et al., 2002; Chow et al., 2005).

Muscle fatigue is also attributed to impaired balance control and elevated risk of fall injuries (Yaggie and McGregor, 2002; Corbeil et al., 2003). Research into muscle fatigue is well documented and has thus far included assessing: a muscle's peripheral characteristics such as reductions in maximal voluntary contraction and/or relaxation (Davidson et al., 2009; Paillard et 
al., 2010b); a muscle's output using characteristics of its surface electromyogram (sEMG) (Caron, 2004; Paillard et al., 2007); aspects relating to dehydration and different postural stances (Lion et al., 2010; Bisson et al., 2010a); and its affect upon the sensory systems (Hiemstra et al., 2001; Forestier et al., 2002). Muscle fatigue's impact upon the sensory system could be explained by the accumulation of metabolites leading to: altered muscle spindle function (Hiemstra et al., 2001); altered central processing of proprioception via group III and IV afferents (Forestier et al., 2002); and effects on the efferent sensory pathways (Taylor et al., 2000). However, research illustrates that the mechanisms involved in muscle fatigue are dependent upon the fatigue methods conducted to fatigue the muscles (task dependency) (Enoka and Duchateau, 2008).

Consequently, the mechanisms involved in muscle fatigue induced by performing repetitive lifting tasks under conditions of postural perturbation are essential to any meaningful analysis conducted. Additionally, construction workers (e.g., masons, rebar workers) perform manual repetitive lifting tasks in which they are exposed to different weights and lifting postures for extended periods of time (Jaffar et al., 2011). Although previous studies have investigated the influence of repetitive lifting tasks on spinal movement or paraspinal muscle response, the direct effects of different weights and lifting postures following repetitive lifting task on balance control remained unexplored. Against this contextual setting, this study seeks to evaluate the effects of different weights and lifting postures on balance control following simulated repetitive lifting tasks. With regards to the stated aim, the objectives of the present study were: i) to compare the effects of stoop and squat lifting postures on balance control during quiet standing balance tests, and ii) to assess the effects of the magnitude of weights on balance control following fatiguing repetitive lifting tasks (i.e., by comparing standing balance tests performed on a stable and an unstable supporting surfaces. Two hypothesis are proposed, namely: i) that a stoop lifting posture would induce a significantly greater adverse effect upon an individuals' balance control than a squat lifting posture following a fatiguing repetitive lifting task; and ii) that heavy lifting weight would jeopardize the balance control on both stable and unstable surfaces (although the adverse effect would be greater on an unstable surface).

\section{RESEARCH METHODS}


An experimental laboratory controlled test procedure was adopted for this research. Twenty healthy participants (all males) were recruited from the student population of the Hong Kong Polytechnic University to participate in this study. The participants mean age was $27.9 \pm 4.0$ years, weight was $71.0 \pm 8.97 \mathrm{~kg}$, and height was $1.74 \pm 0.09 \mathrm{~m}$. There was no significant difference in age, height, and weight of participants in both groups. Test entry criteria for participants were: i) no history of upper limb, back or lower limb pain/injury; and ii) no history of neurological and/or vestibular disorders or other conditions that might affect balance control. Participants provided their informed consent as approved by the Human Subject Ethics Subcommittee of The Hong Kong Polytechnic University (reference number: HSEARS20160719002). Upon consent being given, participants provided their demographic data and were randomized into either a stoop lifting or a squat lifting group (10 participants each). Each participant's maximum lifting strength (MLS) in a stoop or squat lifting posture was then assessed by a back-leg lift dynamometer (Chattecx Corporation, USA). Each group of participants was assigned an allotted lifting posture (i.e., stoop or squat lifting) and requested to gradually pull up the handle of the dynamometer until they reached their perceived MLS. Each participant performed the test twice with a two-min break in between; the highest value of the two trials recorded on the dynamometer represented the participant's MLS (Piezotronics, New York Inc., USA). As a result, the participants' mean MLS for stoop and squat lifting postures was $95.4 \pm 17.4 \mathrm{~kg}$ and $110.7 \pm 13.86 \mathrm{~kg}$, respectively.

The participant then underwent standing balance tests (pre- and post-fatiguing repetitive lifting tasks) that involved three conditions: i) eyes opened on a force plate (EOS); ii) eyes closed on a force plate (ECS); and iii) eyes closed on a foam placed on a force plate (ECF) (where the foam simulated an unstable surface) (refer to Figure 1). The three standing balance tests were chosen to reflect the variety of visual and support surface conditions encountered by construction workers during their course of workplace activities (Wade and Davis, 2008). Balance tests sought to evaluate shifts in the body's center of pressure (CoP) under these conditions and required participants to stand upright in a relaxed position with their arms by their sides for 15 seconds (c.f. Doyle et al., 2005). Their feet had to remain in the same position marked on a piece of transparent sheet that covered the force plate (except ECF condition). The participant was instructed to look ahead during the EOS test, while vision was occluded by a non-transparent goggle (ANSI Z 136, USA) during ECS and ECF tests. To minimize external sound stimuli, participants wore hearing 
protection during all tests conducted (CE EN 352, Australian standard). The force plate was positioned next to the lifting task experimental set up to minimize the time interval between the fatiguing lifting tasks and the $\mathrm{CoP}$ measurements. Previous studies have demonstrated that $\mathrm{CoP}$ displacements from a force plate provide objective, accurate and reliable balance control measurements (Prieto et al., 1996; Lafond et al., 2004).

The CoP displacement test data was collected using a portable 8 channel multiplexing and amplitude modulation circuit force plate (KISTLER Instrumente. AG, Winterthur, Switzerland). The CoP data were sampled at $50 \mathrm{~Hz}$ and low passed filtered with a second-order Butterworth filter $(10 \mathrm{~Hz})$. MATLAB 7.9 software (Matlab, The MathWorks Inc., MA, USA) was used to analyze the $\mathrm{CoP}$ movements. The displacements of $\mathrm{CoP}$ were quantified from: the total sway area, the root mean square (RMS) of the anterior/posterior (A/P) and medial/lateral (M/L) displacements and mean velocity (MV) sway in the A/P and M/L displacement. These CoP parameters have been used in previous studies to evaluate the balance control of an individual; where large displacement of CoP values indicates poor balance control that may increase the risk of falls (Prieto et al., 1996; Bisson et al., 2010a).

$<$ Insert Figure 1 about here>

In order to eliminate any possible biases and differences between and within the two lifting posture groups, each participant was randomly assigned to either a stoop or squat lifting postures, and then performed three separate sets of fatiguing repetitive lifting tasks at 5\%,10\% and 15\% of MLS. As such, the mean weights for 5\% MLS, 10\% MLS, and 15\% MLS were (stoop lifting posture: 4.77 $\pm 0.87 \mathrm{~kg}, 9.54 \pm 1.74 \mathrm{~kg}$, and $14.31 \pm 2.61 \mathrm{~kg}$ ) and (squat lifting: $5.54 \pm 0.69 \mathrm{~kg}, 11.07 \pm 1.39 \mathrm{~kg}$, and $16.61 \pm 2.08 \mathrm{~kg}$ ), respectively. These three percentages of MLS were chosen because previous pilot study research observed that rebar workers on construction sites usually lifted reinforcement bars within these boundaries. Specifically, the repetitive experimental task (using either stoop or squat lifting posture) involved each participant standing upon a demarcated area, with explicit instructions not to move their feet, and lifting a wooden box (of dimensions $30 \times 30 \times 25 \mathrm{~cm}$ ) that contained the target weight (refer to Figure 2). Each participant had to lift the box from the floor to the waist level using the assigned lifting posture until subjective fatigue was reached despite 
strong verbal encouragement (that is, a point in time at which the participant could not continue lifting further). Immediately after each lifting task, the standing balance tests were repeated. To standardize the lifting cycle, a metronome was used to guide the lifting at a rate of 10 cycles per minute. Participants received a 20-minute rest between each lifting task to prevent muscle fatigue.

<Insert Figure 2 about here>

\section{Statistical Analysis}

Independent $t$-tests were conducted to compare between-group differences (stoop vs. squat) and each balance test for all CoP parameters. Once results of the Shapiro-Wilks test confirmed data normality $(p>0.05)$, a separate three-way $(3 \times 3 \times 2)$ repeated measures analyses of variance (ANOVA) for weights (5\% MLS vs. 10\%MLS vs. 15\% MLS), balance tests (EOS vs. ECS vs. ECF) and fatigue (pre- vs. post-fatigue) were conducted for each CoP parameter. Given statistically significant $F$ ratios (refer to Table 1), post-hoc pairwise comparisons were conducted with Bonferroni adjustment. Partial eta squared $\left(\eta_{p}^{2}\right)$ values were reported to estimate the effect sizes. Statistical Package for the Social Science (SPSS) version 20.0 (IBM, USA) was used for the statistical analysis and statistical significance was set at $p<0.05$.

\section{RESULTS}

Figure 3a-e summarizes the arithmetic mean and standard deviation (SD) for RMS of CoP A/P displacement, RMS of CoP M/L displacement, MV of CoP A/P displacement, MV of CoP M/L displacement and total sway area for each balance test condition immediately after the stoop and squat lifting tasks. All CoP parameters revealed no significant difference between lifting postures in the three balance test conditions $(p>0.05)$ although the absolute value of all CoP parameters following the repetitive squat lifting task were larger than those following a stoop lifting posture under all balance test conditions (refer to Figure $3 \mathrm{a}-\mathrm{e}$ ).

<Insert Figure 3a-e about here>

\section{Balance Stability Parameters Comparison of Different Weights, Balance Tests, and Fatigue}

The ANOVA results for CoP parameters are presented in Table 1. Since the main effect of the lifting posture groups (stoop vs. squat) and all relevant interactions were not significant $(p>0.05)$ 
(see Figure 3a-e), the following results only described the effects of different weights, balance test conditions and fatigue on CoP parameters based on pooled data from the two lifting postures.

<Insert Table 1 about here>

\section{Total Sway Area}

Three-way repeated measures ANOVA revealed no significant interaction between weight by balance test by fatigue for total sway area $\left(F=0.66, p=0.53, \eta_{p}^{2}=0.03\right)$ (refer to Table 1$)$. The total sway area demonstrated a significant interaction between weight and fatigue $(F=127.27, p$ $=0.00, \eta_{p}^{2}=0.87$ ) but all other two-way interaction effects were not significant. Significant main effects for weight $\left(F=127.27, p=0.00, \eta_{p}^{2}=0.87\right)$ and fatigue $\left(F=112.98, p=0.00, \eta_{p}^{2}=0.86\right)$ were found. The effect of weight significantly increased the total sway area immediately after lifting tasks. The total sway areas after lifting 5\%, 10\%, and 15\% of MLS were $92.16 \%, 218.17 \%$, and $412.97 \%$ larger than the respective pre-fatigue conditions (Figure 4).

<Insert Figure 4 about here>

\section{Root Mean Square (RMS) of CoP Displacement}

At baseline, balance test conditions revealed no significant difference of RMS of CoP A/P or M/L displacement across all balance test conditions (EOS, ECS and ECF). However, significant twoway and three-way interactions (i.e. weight and fatigue, and balance test condition) were observed on RMS of CoP A/P and M/L displacement (refer to Table 1 and Figure 5a-b).

$<$ Insert Figure 5a-b about here>

Repetitive lifting at 5\% MLS had no significant effect on RMS of CoP A/P displacement across all balance test conditions ( $\mathrm{p}>0.05$ ). However, repetitive lifting at $10 \%$ MLS or $15 \%$ MLS significantly increased RMS of CoP A/P displacement as compared to the baseline. Interestingly, the effect of weight induced significantly larger RMS of CoP A/P displacement in the ECF condition when compared to the EOS and ECS conditions. Similarly, repetitive lifting at $15 \%$ MLS 
caused significantly larger RMS of CoP A/P displacement under ECF condition than EOS and ECS conditions (refer to Figure 5a). For 15\% MLS lifting, ECF caused an increase in RMS of CoP A/P displacement by $70.37 \%$ and $55.96 \%$ when compared to EOS and ECS, respectively. When compared to the baseline, repetitive lifting at 5\% MLS, 10\% MLS and 15\% MLS increased RMS of CoP A/P displacement by 75.97\%, 197.73\%, and 325.65\%, respectively. Taken together, 3-way interaction revealed that repetitive lifting at $10 \%$ and $15 \%$ MLS caused significantly greater RMS of CoP A/P displacement under ECF condition (at 10\%MLS: $82.70 \%$ and $76.02 \%$ ) and (at 15\%MLS: $77.74 \%$ and 59.88\%) as compared to EOS and EOS respectively (Figure 5a).

Similarly, significant 3-way interaction revealed that repetitive lifting at 10\% MLS and 15\% MLS significantly increased RMS of CoP M/L displacement at ECF condition (10\% MLS: 82.09\% and 72.09\%; 15\% MLS: $66.25 \%$ and 56.52\%) compared to EOS and ECS conditions, respectively ( $p$ $<0.05$; Fig. 5b), while there was no significant difference of 5\% MLS lifting weight on RMS of CoP M/L displacement across all balance test conditions. Moreover, the main effect results revealed that RMS of CoP M/L displacement under ECF condition was $70.09 \%$ and $60.08 \%$ greater than ECS and EOS after fatiguing repetitive lifting ( $p<0.05)$ (Figure 5b). Furthermore, lifting weight (at 5\% MLS, 10\%, MLS, and 15\% MLS) significant increased RMS of CoP M/L displacement by $69.39 \%, 183.16 \%$ and $307.14 \%$ after fatiguing.

\section{Mean Velocity $(M V)$}

The MV of CoP A/P and M/L displacement analyses revealed significant main effects of weight, balance and fatigue, and significant two-way and three-way interactions (refer to Table 1, Figure 6a-b). Repetitive lifting at 5\% MLS, 10\% MLS, and 15\% MLS increased MV of CoP A/P displacement under the ECF condition by $207.79 \%$ and $153.74 \% ; 180.86 \%$ and $144.91 \%$; and $163.26 \%$ and $135.23 \%$ when compared to EOS and ECS conditions respectively (refer to Figure 6a). In addition, increased lifting weight significantly increased MV of CoP A/P displacement in all EOS and ECS pairwise comparisons $(p<0.05)$. Fatigue significantly increased MV of CoP A/P displacement in all balance tests $(p<0.05)$. Repetitive lifting at 5\% MLS, 10\% MLS and 15\% MLS increased MV of CoP A/P displacement by $27.66 \%, 59.04 \%$, and $88.53 \%$ respectively. The 3-way interaction test revealed that heavier fatiguing repetitive lifting task had significantly greater effect on MV of CoP A/P displacement under ECF condition when compared to EOS or ECS 
conditions $(p<0.05)$. Specifically, repetitive lifting at different weights (at 5\% MLS: 190.98\% and 146.56\%; at 10\% MLS: $154.40 \%$ and 133.87\%; at 15\% MLS: $134.73 \%$ and $121.31 \%$ ) had differential increases in MV of CoP A/P displacement under the ECF condition when compared to EOS or ECS conditions.

Similarly, greater MV of CoP M/L displacements (at 5\% MLS: $252.62 \%$ and 229.88\%; at 10\% MLS: $228.13 \%$ and 207.74\%; at 15\% MLS: $214.02 \%$ and 194.66\%) at the ECF condition were noted as compared to both the EOS and ECS conditions (Figure 6b). However, no significant difference of $\mathrm{MV}$ of $\mathrm{CoP} \mathrm{M} / \mathrm{L}$ displacement was observed for all EOS and ECS pairwise comparisons $(p>0.05)$. Fatigue significantly increased MV of $\mathrm{CoP} \mathrm{M} / \mathrm{L}$ displacement in all balance test conditions $(p<0.05)$. Moreover, lifting at 5\%,10\%, and 15\% MLS significantly increased MV of CoP M/L displacement by $27.74 \%, 63.76 \%$ and $99.06 \%$, respectively. The 3way interaction revealed that although post-fatigue $\mathrm{MV}$ of $\mathrm{CoP} \mathrm{M} / \mathrm{L}$ displacement under the ECF condition was consistently higher than either the EOS or ECS conditions, heavier repetitive lifting weights (5\% MLS: $186.87 \%$ and 182.10\%; at 10\% MLS: $168.45 \%$ and $161.63 \%$; at 15\% MLS: $160.82 \%$ and $152.57 \%$ ) caused differential increases in MV of CoP M/L displacement under ECF condition when compared to the EOS and ECS conditions.

$<$ Insert Figure 6a-b about here>

\section{DISCUSSION}

Analysis results revealed no significant difference between lifting postures after the fatiguing lifting task across all balance test conditions. This finding indicates that fatiguing repetitive stoop and squat lifting postures induce a similar balance control deficit. Consequently, this finding refutes our first hypothesis that the stoop lifting posture would induce greater variations in balance control than squat lifting postures following fatiguing repetitive tasks. In addition, while increased repetitive lifting weight significantly produced a larger increase in CoP parameters (both RMS and $\mathrm{MV}$ of CoP A/P and M/L displacement analyses), under ECF condition (when compared to either EOS or ECS condition), increased lifting weight caused no significant difference in $\mathrm{CoP}$ parameters (total sway area, RMS of CoP A/P and M/L displacement and MV of CoP M/L displacement) between EOS and ECS conditions. These findings confirm our second hypothesis that the fatiguing repetitive lifting tasks cause poorer balance control on an unstable surface when compared to the stable surface (Yaggie and McGregor, 2002; Corbeil et al., 2003). 


\section{Comparison of Repetitive Lifting Postures: Stoop and Squat}

Test results demonstrate that fatiguing repetitive stoop and squat lifting postures induced similar impairments in balance control, which is contrary to findings reported upon in previous studies (c.f. Sparto et al., 1997a; Commissaris and Toussaint, 1997; Chow et al., 2005). Chow et al. (ibid) reported a significant difference in $\mathrm{CoP}$ parameters during a test that involved lifting four different weights $(20,40,60,80 \mathrm{~N})$ at a rate of five lifting cycles per minute using two different lifting postures (symmetric stoop and squat lifting) after a sudden release of weight. Although the lifting postures were similar to the present study, the discrepancy in results may be attributed to differences in lifting weights, lifting speed, and the absence of a sudden release of weight. Sparto et al., (1997a) found a significant effect of lifting postures upon balance control by instructing their participants to lift at their maximal lifting rate until they: i) cannot continue; and ii) attained an aerobic limit (heart rate of 180 beats/minute). Several methodological differences exist in the literature regarding the contradictory effects of lifting postures on balance control as comparted to previous studies. First, the current study performed the stoop or squat lifting posture from ground floor to the waist level of each participant, which was contrary to Commissaries and Toussaint (1997) study, where participants underwent the same lifting postures at acromion height. Second, there was no vertical distance between the load and the ground in the present study, however, these authors standardized the lowest position at $14 \%$ of the participant's body height. . Consequently, these results cannot be directly compared to the present study due to differences between research protocols adopted. However, our experimental protocol reflects the vertical height of static repetitive lifting posture since we conducted a pilot site observational study of construction workers (e.g., rebar workers) lifting postures in Hong Kong.

\section{Effects of Different Weights, Balance Tests, and Fatigue on Balance Control}

Research results presented indicated that increased weight significantly increased postural sway (i.e., poorer balance control) following a fatiguing repetitive lifting task. This suggests that repetitive lifting with relatively heavy weights may indirectly increase the risk of fall injuries (Corbeil et al., 2003; Paillard, 2012). Findings presented concur with previous research that evaluated the impact of adding weights until fatigue and its impact upon balance control (Ledin and Odkvist, 1993; Punakallio et al., 2003; Lee et al., 2008). Punakallio et al. (2003) reported significant increase in $\mathrm{CoP}$ parameters in the $\mathrm{A} / \mathrm{P}$ and $\mathrm{M} / \mathrm{L}$ directions after wearing firefighting 
clothing weighing $25.9 \mathrm{~kg}$ for 40 seconds in an upright standing position. Similarly, Ledin and Odkvist (1993) found that putting weight (totaling 20\% of body mass) on the chest and back of participants' impaired their ability to remain in equilibrium during 45 seconds. Unfortunately, these studies did not compare the effects of different weights on CoP parameters; whereas the present study reveals increases in CoP parameters as lifting weight is increased from 5\% to $15 \%$ of the participant's MLS. Overall, the findings of the current study can be used to improve the balance control with subsequent fall injuries of construction workers involved in repetitive lifting tasks of weight in range between 5 to $17 \mathrm{~kg}$.

The current study revealed that lifting weights have a differential effect upon balance controls. Repetitive lifting had similar effect on balance control in $\mathrm{A} / \mathrm{P}$ and $\mathrm{M} / \mathrm{L}$ direction on a stable support surface regardless of the presence/absence of vision. In the current study, the visual system is thought not to be a contributing factor to impair balance control for two reasons: firstly, during the eyes open standing balance test (i.e., EOS), the participants focused on a standard white sheet at a uniformed distance, and secondly the participants eyes were closed during the eyes closed standing balance test condition (i.e., ECS). Previous studies have suggested that visual target placed at informed distance can impair balance control (Vuillerme et al., 2001; Vuillerme et al., 2006). Vuillerme et al. (2001) showed that a visual target placed at $1 \mathrm{~m}$ can attenuate the effect of fatigue on balance control during quiet standing balance task. Conversely, the impact of lifting weight on balance control was more profound on an unstable supporting surface with vision occlusion (i.e., ECF) than the other two standing balance conditions. Since an individual relies more on proprioceptive inputs from lower limb and trunk to maintain balance on an unstable surface during vision occlusion (Derave et al., 2002; Maurer et al., 2006; Horak and Macpherson 1996; Bhattacharya et al., 2003), the presence of fatigue may affect an individual's ability to provide correct proprioceptive signals to the brain for balance control (Simeonov et al., 2003). Therefore, repetitive lifting of heavy weights may heighten the risk of fall injuries (Corbeil et al., 2003; Paillard, 2012). Hence, the lifting weight should be reduced for repetitive lifting tasks in order to minimize the risk of falls among workers working on an unstable supporting surface. Since reducing the lifting weight may sometimes be practically infeasible, construction workers should 
adopt proper ergonomic interventions (e.g. exoskeletons, back belts and lifting equipment) to enhance the mechanical advantages of workers during lifting tasks (Kraus et al., 1996).

The effect of muscle fatigue upon balance control was consistent with several previous studies using different fatigue protocols (c.f. Vuillerme et al., 2001; Yaggie and McGregor, 2002; Corbeil et al., 2003). These findings support the notion that repetitive lifting induces muscle fatigue, which may cause proprioceptive deficiency and suboptimal efferent muscle responses that compromise balance control (Hiemstra et al., 2001; Forestier et al., 2002). Although the evidence of muscle fatigue in the current experimental protocol was subjective, our previous studies measured muscle fatigue by using normalized median frequency (MF) and root mean square (RMS) of normalized sEMG amplitude based on similar protocols (Antwi-Afari et al., under review). Although these objective assessment of muscle fatigue are outside the scope of the current study, the results shown decreased MF values and increased muscle activity at the lumber erector spinae and quadriceps muscles, which also concur with previous studies during repetitive lifting tasks (Sparto et al., 1999; Davis et al., 2010). The interaction effects of weight and fatigue after repetitive lifting task were significant for all CoP parameters. This finding indicates impaired balance control with increased weight after fatigue is in line with previous studies (c.f. Punakallio et al., 2003; Schiffman et al., 2006; Lee et al., 2008). The current study assessed balance control by using CoP parameters measured from a force plate. With regards to the directional-specific effects of muscle fatigue, the research findings indicated that balance control in the $\mathrm{A} / \mathrm{P}$ and $\mathrm{M} / \mathrm{L}$ directions showed a similar increase in perceived lower back and calf/quadriceps muscles fatigue following stoop and squat lifting postures, respectively. These results are in accordance with findings of Gribble and Hertel (2004a) and Soleimanifar et al., (2012) which observed that balance control in sagittal and frontal planes was impaired after the fatigue of either hip, knee or ankle muscles. Overall, these findings suggest that the effects of fatigue on balance control are specific to the fatigue location and measures of balance control used.

However, akin to other proprioception studies that examined repetitive lifting tasks (Sparto et al., 1997a; Lin et al., 2012) the current study has some limitations. First, the sample size was relatively small albeit, significant and second, the study was conducted on student participants in a laboratory setting. Future work should therefore evaluate the impact of different lifting parameters on a larger 
sample size experienced construction workers working on on-site. Third, the study results may not be general with respect to repetitive lifting tasks in construction workers. Although designed to evaluate risk factors in relatively realistic conditions, the current study involved only a static controlled repetitive lifting/lowering task. Also, balance control was evaluated during quiet standing tests, while the majority of fall injuries may occur during dynamic tasks that are initiated by slip, trip and loss of balance events. Earlier research has suggested that balance control system utilizes the same control mechanisms under quiet standing and dynamic test conditions (Lauk et al., 1998). However, future research is warranted to evaluate balance control during real dynamic repetitive lifting tasks, and to investigate how they can be translated to fall prevention in real construction sites. Fourth, it remains unknown how a change in specific lifting posture (i.e., either stoop or squat) may affect balance control. How balance may be associated with increased risk of falls among construction workers remains to be seen given that we did not find a significant change in lifting postures across standing balance tests. Future research is needed to examine other index of fatigue in lifting postures such as reduction maximal voluntary contraction and/or relaxation (Davidson et al., 2009; Paillard et al., 2010b), aspects relating to dehydration (Lion et al., 2010) and physiological effects (Nardone et al., 1997; Mello et al., 2010a).

\section{CONCLUSIONS}

This is the first study to evaluate the effects of different lifting weights and lifting postures on balance control following simulated fatiguing repetitive lifting tasks. The results revealed that: i) increased weight regardless of lifting postures significantly increased CoP parameters; ii) stoop and squat lifting postures performed until subjective fatigue induce a similar increase in $\mathrm{CoP}$ parameters; and iii) fatigue adversely effected the participant's balance control on an unstable surface than on a stable surface. These results suggest that fatiguing repetitive lifting tasks may alter the proprioception of the lower limb/back that leads to increased postural sway and suboptimal balance control on an unstable supporting surface. Consequently, fatigued-related loss of balance control may limit the safety range of movement of the body's center of gravity, and thus increase the risk of fall injuries. The findings of the present study have research and practical implications. First, the magnitude of weight during repetitive lifting task can significantly impair balance control and as such reduce the risk of loss of balance events with subsequent fall injuries. Second, surface support conditions are dependent on balance control; as such unstable supporting 
surfaces can significantly reduce the effort for balance control and therefore could be useful in preventing fall injuries among construction workers. To reduce the possibility of losing balance, unstable supporting structures (e.g., scaffold, ramp) used as working surfaces should be minimized when performing static repetitive lifting tasks. Third, the findings demonstrate the potential of the suggested objective balance stability parameters in measuring static repetitive lifting task associated with fall risk resulted from extrinsic (e.g., weights of lift) and intrinsic (e.g., fatigue) factors. Construction workers can benefit from receiving adequate training in recognizing the role of lifting weights and fatigue during static repetitive lifting tasks, which would result in enhanced balance control through redesign of work and improved workers' behaviour. Overall, these findings provide preliminary and invaluable information to researchers and practitioners seeking to develop practical interventions to reduce the risk of falls in construction workers (e.g., masons, rebar workers) involved in repetitive lifting tasks. Future studies should investigate the optimal working and rest durations among workers involving in repetitive lifting works in order to reduce the risk of fatigue-related balance deficit.

\section{ACKNOWLEDGEMENTS}

The authors acknowledge the Department of Building and Real Estate, The Hong Kong Polytechnic University for funding this research. The authors wish to acknowledge the technical and statistical assistance of Dr. May Tam, Mr. Man Cheung and Mr. Kelvin Lam. Also, the authors are grateful to the study participants for their participation.

\section{REFERENCES}

Albers, J. T. and Estill, C. F. (2007) Simple Solutions: Ergonomics for Construction Workers. U.S. Department of Health and Human Services - National Institute for Occupational Safety and Health. Available via: https://www.cdc.gov/niosh/awards/hamilton/aliceabs08.html [Accessed: May, 2017].

Antwi-Afari, M. F., Li, H., Edwards, D. J., Pärn, E. A., Seo, J. and Wong, A. L. U. (Under Review) Biomechanical Analysis of Risk Factors for Work-Related Musculoskeletal Disorders during Repetitive Lifting Task in Construction Workers.

Antwi-Afari, M. F., Li, H., Edwards, D. J., Pärn, E. A., Seo, J. and Wong, A. L. U. (Under Review) Identification of Potential Biomechanical Risk Factors for Low Back Disorders during 
Repetitive Rebar Lifting. Bhattacharya, A., Succop, P., Kincl, L., Lu, M. L. and Bagchee, A. (2003) Postural Stability during Task Performance on Elevated and/or Inclined Surfaces. Occupational Ergonomics, Vol. 3, No. 2, pp. 83-97. DOI: 1359-9364/02/03.

Bisson, E. J., Chopra, S., Azzi, E., Morgan, A. and Bilodeau, M. (2010a) Acute Effects of Fatigue of the Plantarflexor Muscles on Different Postural Tasks. Gait Posture, Vol. 32, No. 4, pp. 482-486. DOI:10.1016/j.gaitpost.2010.07.006.

Bureau of Labor Statistics (2006a) National Census of Fatal Occupational Injuries in 2005, Report USDL 06-1364. Available via: https://www.bls.gov/news.release/pdf/cfoi.pdf [Accessed: May, 2017].

Bureau of Labor Statistics (2006b) Workplace Injuries and Illnesses in 2005, Report USDL 061816. Available via: https://www.bls.gov/news.release/archives/osh_10192006.pdf [Accessed: May, 2017].

Caron, O. (2004) Is there Interaction Between Vision and Local Fatigue of the Lower Limbs on Postural Control and Postural Stability in Human Posture? Neuroscience Letters, Vol. 363, No. 1, pp. 18-21. DOI: 10.1016/j.neulet.2004.03.038.

Center to Protect Workers' Right (CPWR) (2007) The Construction Chart Book: The U.S. Construction Industry and its Workers, $4^{\text {th }}$ Ed., Silver Spring, MD. Available via: http://www.cpwr.com/sites/default/files/research/CB4_Final\%20for\%20web.pdf [Accessed: May, 2017].

Chow, D. H. K., Cheng, I. Y. W., Holmes, A. D. and Evans, J. H. (2005) Postural Perturbation and Muscular Response Following Sudden Release During Symmetric Squat and Stoop Lifting, Ergonomics. Vol. 48, No. 6, pp. 591-607. DOI: 10.1080/00140130500071002.

Commissaris, A. C. M. D. and Toussaint, H. M. (1997) Load Knowledge Affects Low Back Loading and Control of Balance in Lifting Tasks, Ergonomics, Vol. 40, No. 5, pp. 559575. DOI: 10.1080/001401397188035.

Corbeil, P., Blouin, J. S., Begin, F., Nougier, V. and Teasdale, N. (2003) Perturbation of the Postural Control System Induced by Muscular Fatigue, Gait Posture, Vol. 18, No. 2, pp. 92-100. DOI: 10.1016/S0966-6362(02)00198-4.

Davidson, B. S., Madigan, M. L., Nussbaum, M. A. and Wojcik, L. A. (2009) Effects of Localized Muscle Fatigue on Recovery from a Postural Perturbation without Stepping, Gait Posture, Vol. 29, No. 4, pp. 552-557. DOI: 10.1016/j.gaitpost.2008.12.011. 
Davis, K. G., Kotowski, S. E., Albers, J., and Marras, W. (2010) Investigating Reduced Bag Weight as an Effective Risk Mediator for Mason Tenders, Applied Ergonomics, Vol. 41, No. 6, pp. 822-831. DOI: 10.1016/j.apergo.2010.02.001.

Derave, W., Tombeux, N., Cottyn, J., Pannier, J. L. and De Clercq, D. (2002) Treadmill Exercise Negatively Affects Visual Contribution to Static Postural Stability, International Journal of Sports Medicine, Vol. 23, No. 1, pp. 44-49. DOI: 10.1055/s-2002-19374.

Doyle, T. L., Newton, R. U. and Burnett, A. F. (2005) Reliability of Traditional and Fractal Dimension Measures of Quiet Stance Centre of Pressure in Young, Healthy People. Archives of Physical. Medical Rehabilitation, Vol. 86, No. 10, pp. 2034-2040. DOI: 10.1016/j.apmr.2005.05.014.

Enoka, R. M. and Duchateau, J. (2008) Muscle Fatigue: What, Why and How it Influences Muscle Function, Journal of Physiology, Vol 586, No. 1, pp. 11-23. DOI: 10.1113/jphysiol.2007.139477.

Forestier, N., Teasdale, N. and Nougier, V. (2002) Alteration of the Position Sense at the Ankle Induced by Muscular Fatigue in Humans, Medicine and Science in Sports Exercise, Vol. 34, No. 1, pp. 117-122. DOI: 00005768-200201000-00018.

Goldsheyder, D., Nordin, M., Weiner, S. S. and Hiebert, R. (2002) Musculoskeletal Symptom Survey among Mason Tenders. American Journal of Industrial Medicine, Vol. 42, No. 5, pp. 384-396. DOI: 10.1002/ajim.10135.

Gribble, P. A. and Hertel, J. (2004a) Effect of Lower Extremity Muscle Fatigue on Postural Control, Archives of Physical Medical Rehabilitation, Vol. 85, No. 4, pp. 589-592. DOI: 10.1016/j.apmr.2003.06.031.

Hagen, K. B. and Harms-Ringdahl, K. (1994) Ratings of Perceived Thigh and Back Exertion in Forest Workers during Repetitive Lifting Using Squat and Stoop Techniques. Spine, Vol. 19, No. 22, pp. 2511-2517.

Hess, F., van Hedel, H. J. A. and Dietz, V. (2003) Obstacle Avoidance during Human Walking: H-Reflex Modulation during Motor Learning. Experimental Brain Research, Vol. 151, No. 1, pp. 82-89. DOI: 10.1007/s00221-003-1415-7.

Hiemstra, L. A., Lo, I. K. and Fowler, P. J. (2001) Effect of Fatigue on Knee Proprioception: Implications for Dynamic Stabilization, Journal of Orthopaedic and Sports Physical Therapy, Vol. 31, No. 10, pp. 598-605. DOI: 10.2519/jospt.2001.31.10.598. 
Holbein-Jenny, M. A., Mcdermott, C. S. and Demchak, J. (2007) Validity of Functional Stability Limits as a Measure of Balance in Adults Aged 23-73 Years, Ergonomics, Vol. 50, No. 5, pp. 631-646. DOI: 10.1080/00140130601154814.

Horak, F. B. and Macpherson, J. M. (1996) Postural Orientation and Equilibrium, In: Rowell LB, Shepherd J (Eds.) Handbook of Physiology, Section 12, Exercise, Regulation and Integration of Multiple Systems. Oxford University Press, New York, pp. 255-292.

Horak, F. (2006) Postural Orientation and Equilibrium: What do we Need to Know about Neural Control of Balance to Prevent Falls? Age Aging, Vol. 35, No. 2, pp. ii7-ii11.

Hsiao, H. and Simeonov, P. (2001) Preventing Falls from Roofs: a Critical Review, Ergonomics, Vol. 44, No. 5, pp. 537-561. DOI: 10.1080/00140130110034480.

Jaffar, N., Abdul-Tharim, A. H., Mohd-Kamar, I. F. and Lop, N. S. (2011) A Literature Review of Ergonomics Risk Factors in Construction Industry, Procedia Engineering, Vol. 20, pp. 89-97. DOI: https://doi.org/10.1016/j.proeng.2011.11.142.

Jiang, S., Zhang, B. and Wei, D. (2011) The Elderly Fall Risk Assessment and Prediction Based on Gait Analysis. In: The IEEE International Conference on Computer and Information Technology, pp. 176-180. DOI: 10.1109/CIT.2011.82.

Kincl, L. D., Bhattacharya, A., Succop, P. A. and Clark, C.S. (2002) Postural Sway Measurements: A Potential Safety Monitoring Technique for Workers Wearing Personal Protective Equipment, Applied Occupational and Environmental Hygiene, Vol. 17, No. 4, pp. 256266. DOI: $10.1080 / 10473220252826565$.

Kraus, J. F., Brown, K. A., McArthur, D. L., Peek-Asa, C., Samaniego, L., Kraus, C. and Zhou, L. (1996) Reduction of Acute Low Back Injuries by Use of Back Supports, International Journal of Occupational and Environmental Health, Vol. 2, No. 4, pp. 264-273. DOI: 10.1179/oeh.1996.2.4.264.

Lafond, D., Duarte, M. and Prince, F. (2004) Comparison of Three Methods to Estimate the Center of Mass During Balance Assessment, Journal of Biomechanics, Vol. 37, No. 9, pp. 14211426. DOI: 10.1016/S0021-9290(03)00251-3.

Latza, U., Pfahlberg, A. and Gefeller, O. (2002) Impact of Repetitive Manual Materials Handling and Psychosocial Work Factors on the Future Prevalence of Chronic Low-Back Pain among Construction Workers, Scandinavian Journal of Work, Environment \& Health, Vol. 28, No. 5, pp. 314-323. DOI: http://www.jstor.org/stable/40967216. 
Lauk, M., Chow, C. C., Pavlik, A. E. and Collins, J. J. (1998) Human Balance out of Equilibrium: Non-equilibrium Statistical Mechanics in Postural Control, Physical Review Letters, Vol. 80, No. 2, pp. 413-416. DOI: https: 10.1103/PhysRevLett.80.413.

Ledin, T. and Odkvist, L. M. (1993) Effects of Increased Inertial Load in Dynamic and Randomized Perturbed Posturography, Acta Oto-Laryngologica, Vol. 113, No. 3, pp. 249252. DOI: $10.3109 / 00016489309135802$.

Lee, H., Granata, K. P. and Madigan, M. L. (2008) Effects of Trunk Exertion Force and Direction on Postural Control of the Trunk during Unstable Sitting, Clinical Biomechanics (Bristol Avon), Vol. 23, No. 5, pp. 505-509. DOI: 10.1016/j.clinbiomech.2008.01.003.

Lin, D., Nussbaum, M. A. and Madigan, M. L. (2012) Efficacy of Three Interventions at Mitigating the Adverse Effects of Muscle Fatigue on Postural Control, Ergonomics, Vol. 55, No. 1, pp. 103-113. DOI: 10.1080/00140139.2011.636454.

Lion, A., Bosser, G., Gauchard, G. C., Djaballah, K., Mallié, J. P. and Perrin, P. P. (2010) Exercise and Dehydration: A Possible Role of Inner in Balance Control Disorder, Journal of Electromyography and Kinesiology, Vol. 20, No. 6, pp. 1196-1202. DOI: 10.1016/j.jelekin.2010.07.016.

Lipscomb, H. J., Glazner, J. E., Bondy, J., Guarini, K. and Lezotte, D. (2006) Injuries from Slips and Trips in Construction, Applied Ergonomics, Vol. 37, No. 3, pp. 267-274. DOI: 10.1016/j.apergo.2005.07.008.

Marras, W. S., Lavender, S. A., Leurgans, S. E., Fathallah, F. A., Ferguson, S. A., Allread, W. G. and Rajulu, S. L. (1995) Biomechanical Risk Factors for Occupationally Related Low Back Disorders, Ergonomics, Vol. 38, No. 2, pp. 377-410. DOI: 10.1080/00140139508925111.

Maurer, C., Mergner, T. and Peterka, R. J. (2006) Multisensory Control of Human Upright Stance, Experimental Brain Research, Vol. 171, No. 2, pp. 231-250. DOI: 10.1007/s00221-0050256-y.

Mello, R. G., de Oliveira, L. F. and Nadal, J. (2010a) Effects of Maximal Oxygen Uptake Test and Prolonged Cycle Ergometer Exercise on the Quiet Standing Control, Gait Posture, Vol. 32, No. 2, pp. 220-225. DOI: 10.1016/j.gaitpost.2010.04.016.

Nardone, A., Tarantola, J., Giordano, A. and Schieppati, M. (1997) Fatigue Effects on Body Balance. Electroencephalography and Clinical Neurophysiology, Vol. 105, No. 4, pp. 309320. DOI: 10.1016/S0924-980X (97)00040-4. 
Paillard, T., Maitre, J., Chaubet, V. and Borel, L. (2010b) Stimulated and Voluntary Fatiguing Contractions of Quadriceps Femoris Differently Disturb Postural Control, Neuroscience Letters, Vol. 477, No. 1, pp. 48-51. DOI: 10.1016/j.neulet.2010.04.034.

Paillard, T., Bizid, R. and Dupui, P. (2007) Do Sensorial Manipulations Affect Subjects Differently Depending on their Postural Abilities? British Journal of Sports Medicine, Vol. 41, No. 7, pp. 435-438. DOI: 10.1136/bjsm.2006.032904.

Paillard, T. (2012) Effects of General and Local Fatigue on Postural Control: A Review. Neuroscience \& Biobehavioral Reviews, Vol. 36, No. 1, pp. 162-176. DOI: 10.1016/j.neubiorev.2011.05.009.

Prieto, T. E., Myklebust, J. B., Hoffmann, R. G., Lovett, E. G. and Myklebust, B. M. (1996) Measures of Postural Steadiness: Differences Between Healthy Young and Elderly Adults, IEEE Transactions on Biomedical Engineering, Vol. 43, No. 9, pp. 956-966. DOI: 10.1109/10.532130.

Punakallio, A. (2005) Balance Abilities of Workers in Physically Demanding Jobs: with Special Reference to Firefighters of Different Ages, Journal of Sports Science and Medicine, Vol. 4, No. 8, pp. 1-47.

Punakallio, A., Lusa, S. and Luukkonen, R. (2003) Protective Equipment Affects Balance Abilities Differently in Younger and Older Firefighters, Aviation, Space, and Environmental Medicine, Vol. 74, No. 11, pp. 1151-1156.

Schiffman, J. M., Bensel, C. K., Hasselquist, L., Gregorczyk, K. N. and Piscitelle, L. (2006) Effects of Carried Weight on Random Motion and Traditional Measures of Postural Sway, Applied Ergonomics, Vol 37, No. 5, pp. 607-614. DOI: 10.1016/j.apergo.2005.10.002.

Seliga, R., Bhattacharya, A., Succop, P., Wickstrom, R., Smith, D. and Willeke, K. (1991) Effect of Work Load and Respirator Wear on Postural Stability, Heart Rate, and Perceived Exertion, American Industrial Hygiene Association Journal, Vol. 52, No. 10, pp. 417-422. DOI: $10.1080 / 15298669191364965$.

Simeonov, P.I., Hsiao, H., Dotson, B.W. and Ammons, D.E. (2003) Control and Perception of Balance at Elevated and Sloped Surfaces, Human Factors, Vol. 45, No. 1, pp.136-147. DOI: $10.1518 / \mathrm{hfes} .45 .1 .136 .27232$.

Soleimanifar, M., Salavati, M., Akhbari, B. and Moghadam, M. (2012) The Interaction Between the Location of Lower Extremity Muscle Fatigue and Visual Condition on Unipedal 
Postural Stability, European Journal of Applied Physiology, Vol. 112, No. 10, pp. 34953502. DOI: 10.1007/s00421-012-2330-z.

Sparto, P. J., Parnianpour, M., Barria, E. A. and Jagadeesh, J. M. (1999) Wavelet Analysis of Electromyography for Back Muscle Fatigue Detection During Isokinetic Constant Torque Exertions, Spine (Philadelphia, Pa.), Vol. 24, No. 17, pp. 1791- 1798.

Sparto, P. J., Parnianpour, M., Reinsel, T. E. and Simon, S. (1997a) The Effect of Fatigue on Multijoint Kinematics, Coordination, and Postural Stability During a Repetitive Lifting Test, Journal of Orthopaedic and Sports Physical Therapy, Vol. 25, No. 1, pp. 3-12. DOI: 10.2519/jospt.1997.25.1.3.

Straker, L. and Duncan, P. (2000) Psychophysical and Psychological Comparison of Squat and Stoop Lifting by Young Females, Australian Journal of Physiotherapy, Vol. 46, No. 1, pp. 27-32. DOI: 10.1016/S0004-9514(14)60311-1.

Taylor, J. L., Butler, J. E. and Gandevia, S. C. (2000) Changes in Muscle Afferents, Motoneurons and Motor Drive During Muscle Fatigue, European Journal of Applied Physiology, Vo. 83, No. 2-3, pp. 106-115. DOI: 10.1007/s004210000269.

Vuillerme, N., Nougier, V. and Prieur, J. M. (2001) Can Vision Compensate for a Lower Limbs Muscular Fatigue for Controlling Posture in Humans? Neuroscience Letters, Vol. 308, No. 2, pp. 103-106. DOI: 10.1016/S0304-3940(01)01987-5.

Vuillerme, N., Burdet, C., Isableu, B. and Demetz, S. (2006) The magnitude of the effect of calf muscles fatigue on postural control during bipedal quiet standing with vision depends on the eye-visual target distance. Gait Posture, Vol. 24, No. 2, pp. 169-172. DOI: 10.1016/j.gaitpost.2005.07.011.

Wade, C. and Davis, J. (2008) Postural Sway Following Prolonged Exposure to an Inclined Surface, Safety Science, Vol. 47, No. 5. pp. 652-658. DOI: https: 10.1016/j.ssci.2008.09.002.

Yaggie, J. A. and McGregor, S. J. (2002) Effects of Isokinetic Ankle Fatigue on the Maintenance of Balance and Postural Limits. Archives of Physical Medicine and Rehabilitation, Vol. 83, No. 2, pp. 224-228. DOI: 10.1053/apmr.2002.28032.

Zigel, Y., Litvak, D. and Gannot, I. (2009) A Method for Automatic Fall Detection of Elderly People using Floor Vibrations and Sound Proof of Concept on Human Mimicking Doll 
Falls, IEEE Transactions of Biomedical Engineering, Vol. 56, No. 12, pp. 2858-2867. DOI: 10.1109/TBME.2009.2030171. 
Figure 1 - A Foam $(39 \mathrm{~cm} \times 39 \mathrm{~cm} \times 10 \mathrm{~cm}$ thickness $)$ on a Force Plate

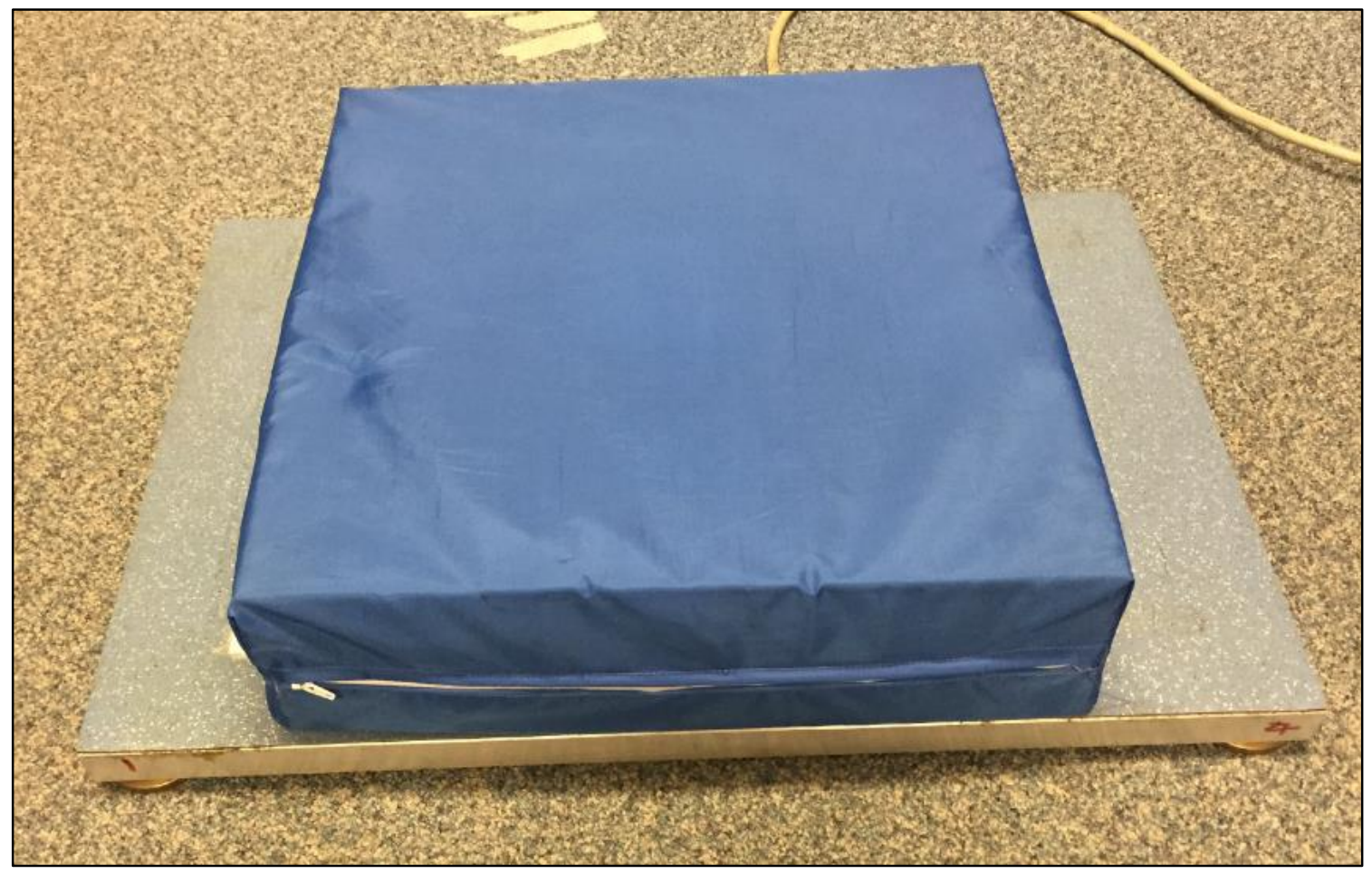


Figure 2 - Two lifting postures: (a) Stoop posture; and (b) Squat posture

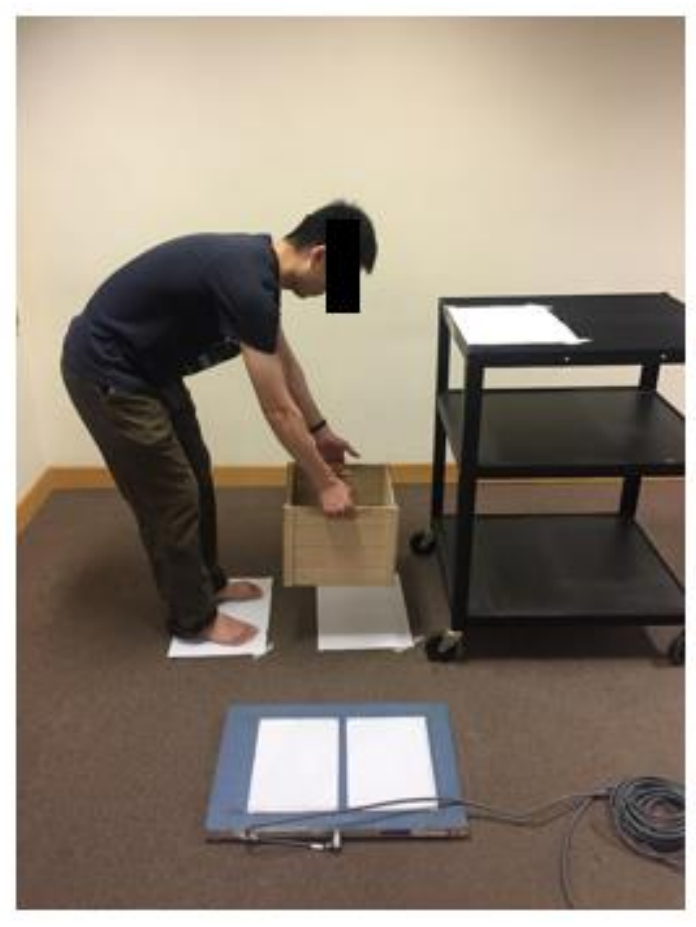

(a)

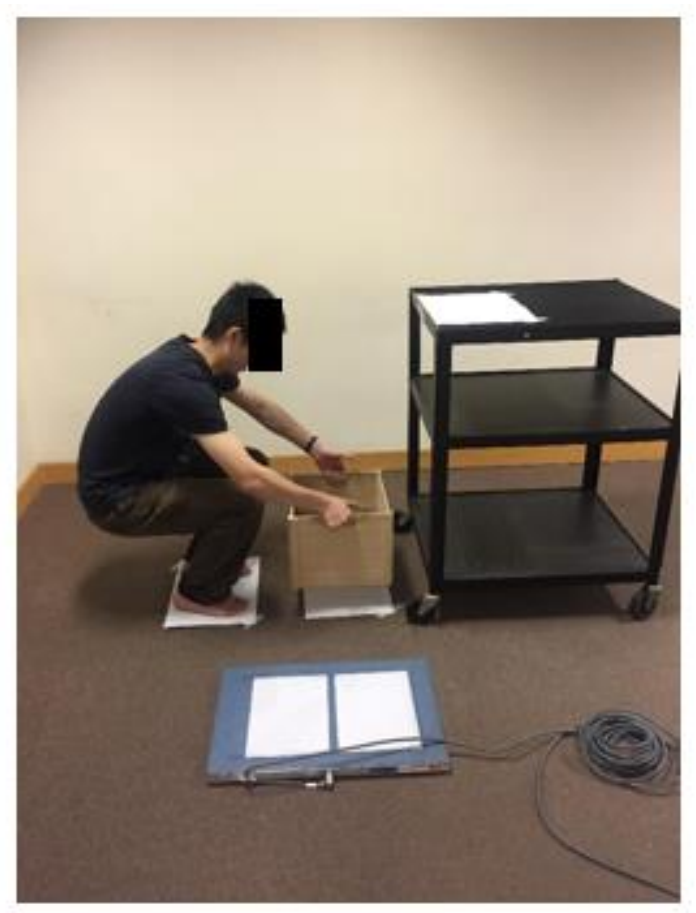

(b) 
Figure 3a-e - The Different Center of Pressure (CoP) Parameters during Balance Test

Following Fatiguing Repetitive Lifting Tasks with Different Weights and Lifting Postures.

Figure 3(a) - RMS of Anterior/Posterior Displacement of CoP

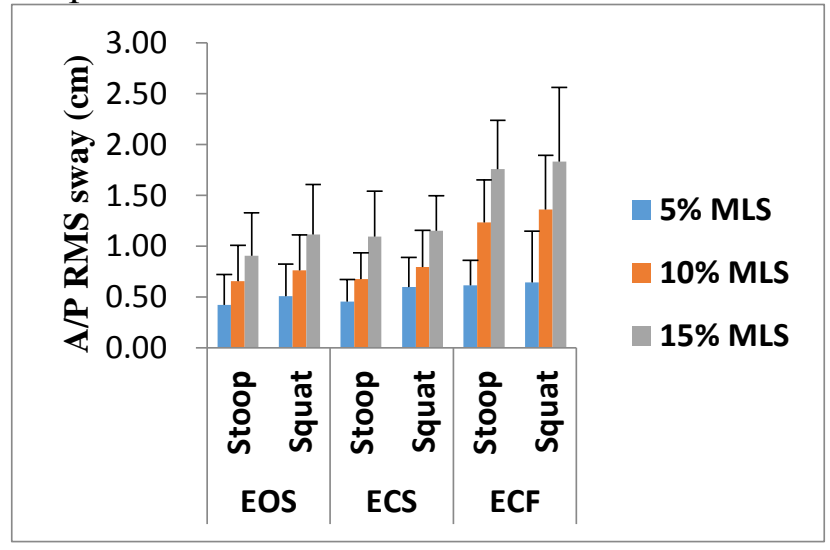

Figure 3(c) - MV of Anterior/Posterior Displacement of CoP

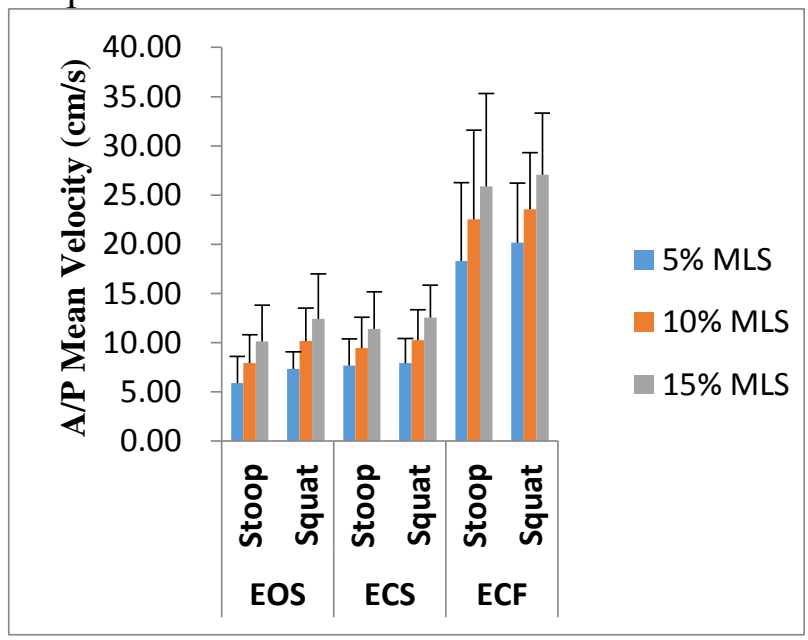

Figure 3(e) - Total Sway Area

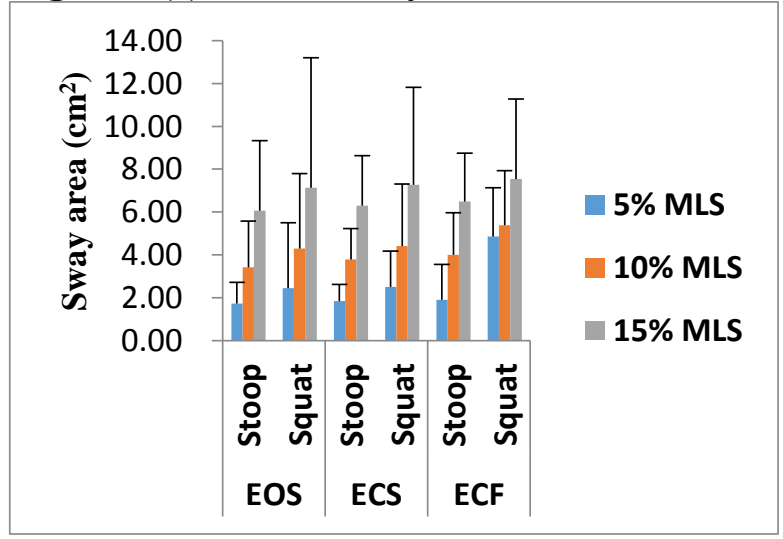

Figure 3(b) - RMS of Medial/Lateral Displacement of CoP

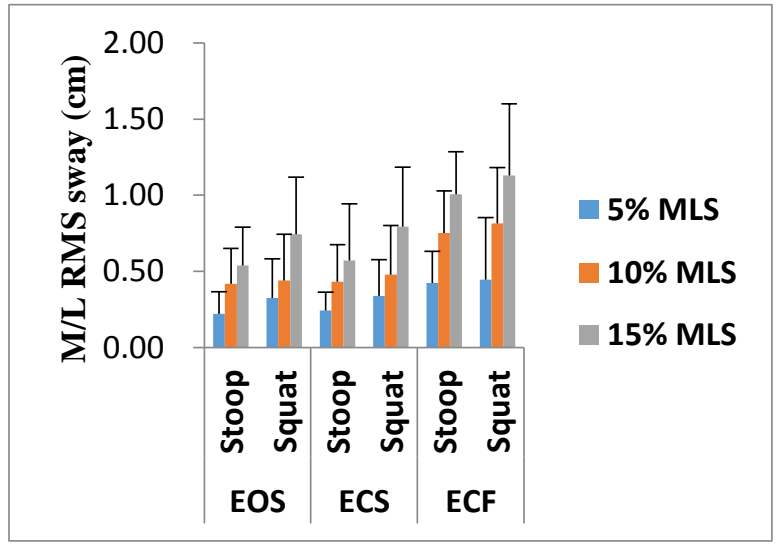

Figure 3(d) - MV of Medial/Lateral Displacement of CoP

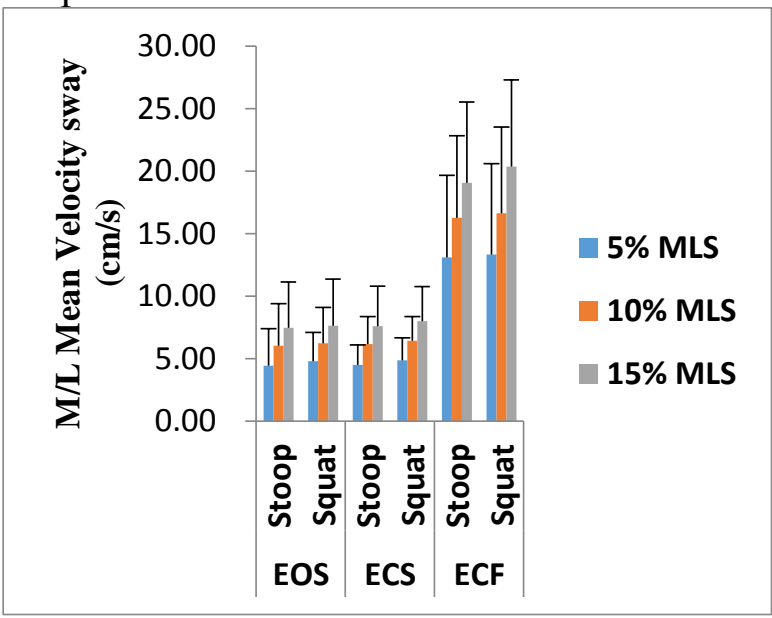


Table 1 - Analysis of Variance Results for Center of Pressure (CoP) Parameters: $F$ Ratios and Pvalues

\begin{tabular}{|c|c|c|c|c|c|c|}
\hline \multicolumn{2}{|l|}{ Effects } & $\begin{array}{c}\text { Sway area } \\
F \text { ratio }\end{array}$ & $\begin{array}{c}\text { A/P RMS } \\
F \text { ratio }\end{array}$ & $\begin{array}{c}\text { M/L RMS } \\
F \text { ratio }\end{array}$ & $\begin{array}{c}\text { A/P MV } \\
F \text { ratio } \\
\end{array}$ & $\begin{array}{c}\text { M/L MV } \\
F \text { ratio } \\
\end{array}$ \\
\hline \multicolumn{7}{|l|}{ Main effect } \\
\hline Weight & & $127.27^{*}$ & $137.40 *$ & $92.21 *$ & $105.69 *$ & $149.58 *$ \\
\hline Fatigue & & $112.98 *$ & $346.17^{*}$ & $114.85^{*}$ & $174.41 *$ & $179.91 *$ \\
\hline Postural task & & 2.17 & $7.56^{*}$ & $6.07^{*}$ & $61.11 *$ & $51.37 *$ \\
\hline \multicolumn{7}{|l|}{ Interaction } \\
\hline $\begin{array}{l}\text { Weight } \\
\text { balance test }\end{array}$ & $x$ & 0.66 & $10.81 *$ & $3.09 *$ & $6.22 *$ & $12.15^{*}$ \\
\hline $\begin{array}{l}\text { Fatigue } \\
\text { balance test }\end{array}$ & $x$ & 0.17 & $16.49 *$ & $11.16^{*}$ & $15.39 *$ & $31.76^{*}$ \\
\hline $\begin{array}{l}\text { Weight } \\
\text { fatigue }\end{array}$ & $x$ & $127.27^{*}$ & $137.40^{*}$ & $92.21 *$ & $105.69^{*}$ & $149.58 *$ \\
\hline $\begin{array}{l}\text { Weight } \\
\text { balance test } \\
\text { fatigue }\end{array}$ & $\begin{array}{l}\times \\
\times\end{array}$ & 0.66 & $10.81 *$ & $3.09 *$ & $6.22 *$ & $12.15^{*}$ \\
\hline
\end{tabular}


Figure 4 - Total Sway Area (Mean and Standard Deviation) of the Different Postural Tasks Before (Baseline) and After Fatiguing Repetitive Lifting Task.

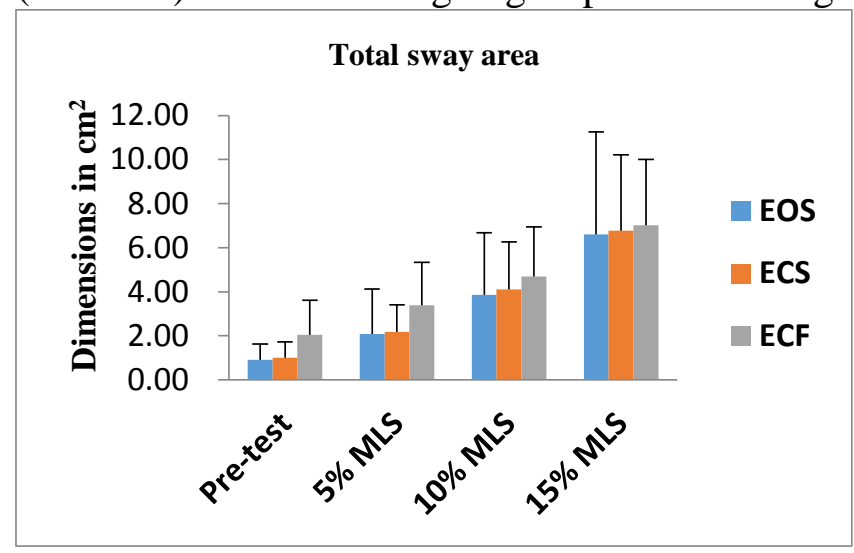

NB: No significant difference was found in all conditions. 
Figure 5a - RMS of anterior/posterior (A/P) CoP displacement

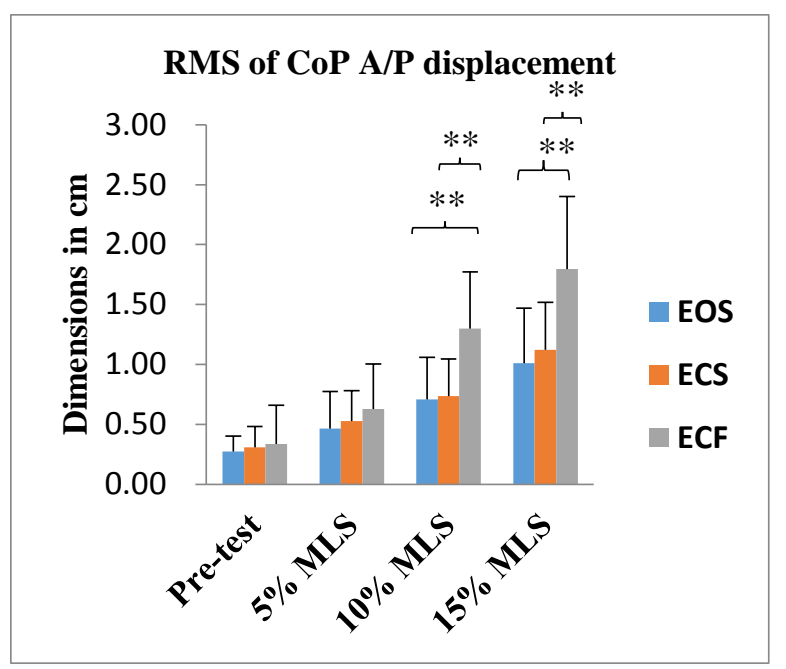

Figure 5b - RMS of medial/lateral (M/L) CoP displacement

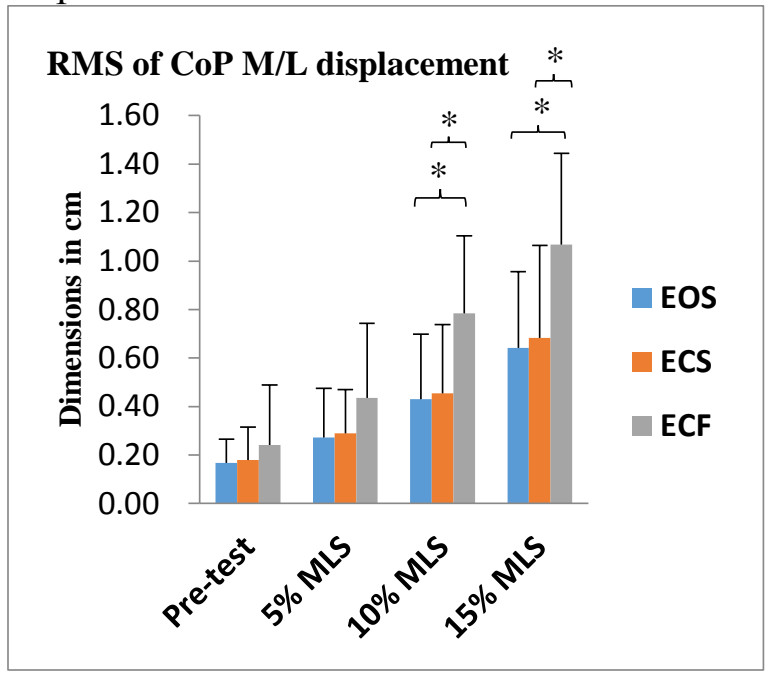

NB: ${ }^{*} p$ significant at $<0.05,{ }^{* *} p$ significant at $<0.01$. 
Figure 6a - MV of Anterior/Posterior (A/P) CoP Displacement

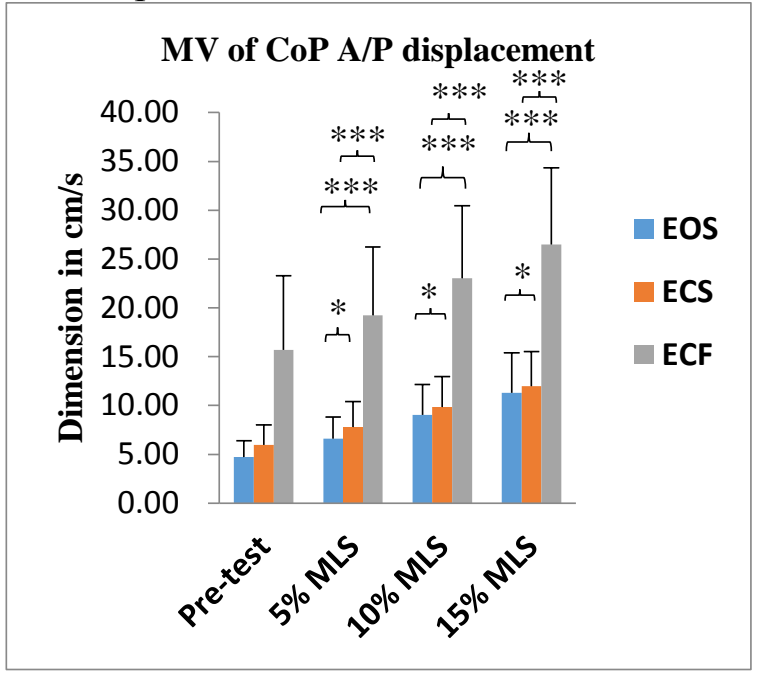

Figure 6b - MV of medial/lateral (M/L) CoP displacement

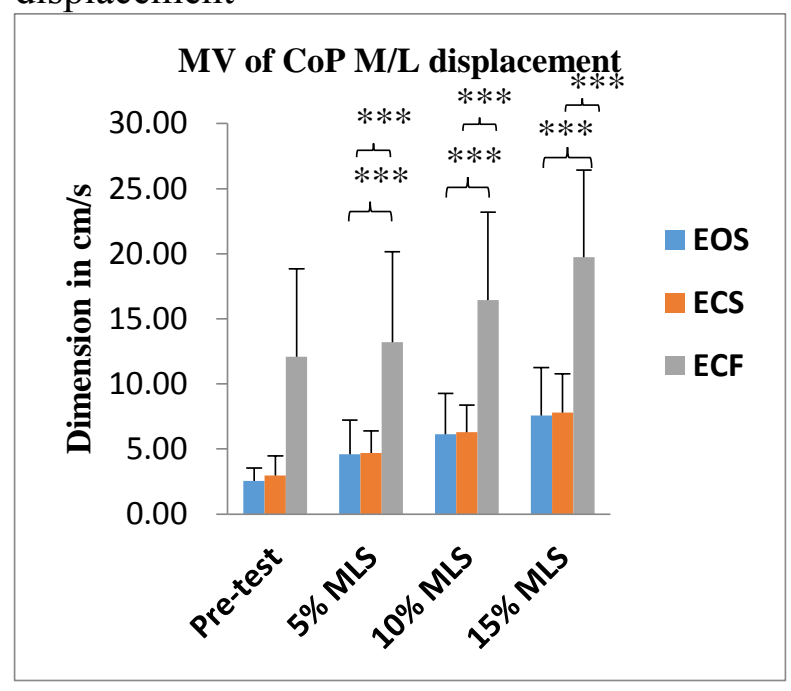

NB: $* p$ significant at $<0.05,{ }^{* * *} p$ significant at $<0.001$. 